BMJ Open

Diabetes

Research

\& Care

\section{Is chronic low back pain a risk factor for diabetes? The Nord-Trøndelag Health Study}

To cite: Heuch I, Heuch I, Hagen $\mathrm{K}$, et al. Is chronic low back pain a risk factor for diabetes? The NordTrøndelag Health Study. BMJ Open Diab Res Care 2018;6:e000569. doi:10.1136/ bmjdrc-2018-000569

Received 20 June 2018 Revised 22 August 2018 Accepted 29 September 2018

Check for updates

\section{(C) Author(s) (or their} employer(s)) 2018. Re-use permitted under CC BY-NC. No commercial re-use. See rights and permissions. Published by BMJ.

For numbered affiliations see end of article.

Correspondence to Dr Ingrid Heuch; ingrid.heuch@ous-hf.no

\section{ABSTRACT}

Objective The purpose of this study was to examine the risk of diabetes associated with the presence or absence of chronic low back pain, considering both cross-sectional and cohort data.

Research design and methods Analyses were based on the Norwegian HUNT2 and HUNT3 surveys of NordTrøndelag County. The prevalence of diabetes was compared in groups with and without chronic low back pain among 45157 participants aged 30-69 years. Associations between low back pain at baseline and risk of diabetes were examined in an 11-year follow-up of 30 380 individuals with no baseline diagnosis of diabetes. The comorbidity between diabetes and low back pain was assessed at the end of follow-up. All analyses were carried out considering generalized linear models incorporating adjustment for other relevant risk factors.

Results Cross-sectional analyses did not reveal any association between low back pain and diabetes. With adjustment for age, body mass index, physical activity and smoking, the cohort study of women showed a significant association between low back pain at baseline and risk of diabetes (RR 1.30; $95 \% \mathrm{Cl} 1.09$ to $1.54, p=0.003$ ). The association differed between age groups $(p=0.015)$, with a stronger association in relatively young women. In men, no association was found in the whole age range (RR 1.02; $95 \% \mathrm{Cl} 0.86$ to $1.21, \mathrm{p}=0.82$ ). No association was observed between diabetes and chronic low back pain at the end of follow-up.

Conclusion Among younger women, those with chronic low back pain may have an increased risk of diabetes.

\section{INTRODUCTION}

Diabetes is one of the most important metabolic disorders today. ${ }^{1}$ Low back pain is the most common musculoskeletal disorder and the leading cause of disability globally. ${ }^{2}$ Low back pain is frequently seen among patients with diabetes, ${ }^{3}$ but it is not known whether this reflects a causal relationship. ${ }^{4}$ There are indications that diabetes is associated with disc degeneration, ${ }^{56}$ and diabetes may also predispose to lumbar spinal stenosis. ${ }^{7}$ Diabetes and low back pain share important risk factors as overweight and obesity, ${ }^{8}$ physical inactivity ${ }^{1011}$ and smoking. ${ }^{1213}$ It is uncertain, however, whether associations between

\section{Significance of this study}

What is already known about this subject?

- Low back pain is commonly seen among patients with diabetes, but it is not known whether this reflects a causal relationship.

What are the new findings?

- Women without diabetes who experience chronic low back pain have an increased risk of being diagnosed with diabetes in the subsequent 11-year interval.

How might these results change the focus of research or clinical practice?

- More attention should be paid to associations between low back pain and diabetes in epidemiological studies.

back pain and diabetes will be maintained in studies designed to assess etiological relationships, adjusting for established risk factors.

In epidemiological studies, the prevalence of musculoskeletal pain has been found to be increased in patients with type 2 diabetes in regions such as the shoulder, neck, back, arms, knees and hips. ${ }^{14}$ There are very few population-based studies of relations between diabetes and back pain. A large cross-sectional study found an association between prevalence of chronic low back pain and diabetes. ${ }^{15}$ A higher risk of back, neck and/or shoulder pain was found among individuals with diabetes in a large 4-year prospective study. ${ }^{16}$ In a 2-4 year follow-up study of twins, back pain was not found to increase the risk of diabetes significantly. ${ }^{4}$

The purpose of the present study was to explore associations between chronic low back pain and risk of diabetes in a Norwegian population, taking into account established risk factors. Specifically, we address the following questions. Does the prevalence of diabetes differ between groups with and without chronic low back pain in a 
cross-sectional setting? In an 11-year follow-up, does the risk of diabetes depend on having chronic low back pain at start of follow-up? Among individuals with neither diabetes nor chronic low back pain at start of follow-up, do diabetes and chronic low back pain show any association in comorbidity at the end of follow-up?

\section{RESEARCH DESIGN AND METHODS}

\section{Study design}

Three health surveys have been carried out in the county of Nord-Trøndelag in Norway, ${ }^{17}$ HUNT1 in 1984-1986, HUNT2 in 1995-1997 and HUNT3 in 2006-2008. The present work is based on data from the second survey, HUNT2, ${ }^{18}$ combined with follow-up data from the third survey, HUNT3. ${ }^{17}$ The whole population in Nord-Trøndelag aged 20 years and above were invited to participate in the HUNT2 survey. Each person was asked to fill in a questionnaire on health status. Everybody was invited to a clinical examination, which included measurements of height and weight and drawing non-fasting blood samples. After 11 years, similar information from a questionnaire and a clinical examination was collected in the HUNT3 survey.

A question in the HUNT2 questionnaire was: 'Do you have or have you had diabetes?' and participants answering yes were then asked to report 'age at first time'. In HUNT3, similar questions about diabetes were asked. In a validation study, self-reported diabetes in HUNT1 was compared with general practitioners' records, and the self-report had excellent positive (96.4\%) and negative $(99.7 \%)$ predictive values. ${ }^{19}$

Another question in HUNT2 and HUNT3 was expressed in this manner: 'During the last year, have you suffered from pain and/or stiffness in your muscles and joints that has lasted for at least three consecutive months?' Any participant who answered yes was then given the following question: 'Where did you have these complaints?' The questionnaires listed several body regions. Individuals answering yes to the first question and specifying the lower back as a relevant region were classified as having chronic low back pain. ${ }^{20}$ The questionnaires also elicited information on physical activity in leisure time, smoking and education.

Each participant in the HUNT2 and HUNT3 surveys signed a written informed consent regarding the collection and use of data for research purposes.

\section{Design of the cross-sectional study}

Among individuals with information available about diabetes and chronic low back pain, associations between chronic low back pain and diabetes were explored in the cross-sectional HUNT2 survey. Because of low participation rates in the youngest and oldest age groups, ${ }^{21}$ the study was restricted to those aged 30-69 years when they participated in HUNT2. Information about residence status was supplied by national registries and linked by use of the unique Norwegian personal identification numbers.

At the time of the HUNT2 survey, the total population consisted of 58928 persons in the age interval of 30-69 years. The cross-sectional study included 45157 participants, 23578 women and 21579 men, with known information about diabetes and chronic low back pain in HUNT2, corresponding to a response rate of $76.6 \%$.

\section{Design of the cohort study}

An 11-year prospective study was conducted considering baseline data from HUNT2 combined with follow-up data from HUNT3. The study aimed at the cohort consisting of 44183 individuals without diabetes, aged 30-69 years when they participated in the HUNT2 survey. During the period of follow-up, 2542 members of this cohort died and 1542 individuals left the county of Nord-Trøndelag. Furthermore, 9719 members of the cohort residing in Nord-Trøndelag at the time of HUNT3 did not participate or did not supply information about diabetes. Thus, a total of 30380 individuals, 16552 women and 13828 men, were available for analysis after follow-up, representing $75.8 \%$ of the remaining individuals resident in the county and $68.8 \%$ of the original cohort.

The cohort study of comorbidity included $10 \quad 131$ women and 8561 men without diabetes or chronic low back pain at baseline and with known status of low back pain and diabetes at the end of follow-up.

\section{Covariate assessment}

Baseline age was categorized into 10-year intervals in the main statistical analyses. Body mass index (BMI), defined as weight/height ${ }^{2}$ and computed in $\mathrm{kg} / \mathrm{m}^{2}$, was subdivided into four groups: $\leq 24.9,25-29.9,30-34.9$ and $\geq 35$. For physical activity in leisure time, including going to work, the first category comprised those engaged in light activity only or hard physical activity (leading to sweating or being out of breath) $<1$ hour per week. Other categories represented hard physical activity $1-2$ and $\geq 3$ hours per week. In a reliability and validity study, ${ }^{22}$ the question on hard activity in leisure time showed acceptable repeatability and represented a reasonably valid measure of vigorous activities. Categories of cigarette smoking represented current daily smoking, previous daily smoking and never daily smoking.

Particular analyses also included duration of education as a covariate, with three groups, $\leq 9,10-12$ and $\geq 13$ years. Serum total cholesterol, high-density lipoprotein (HDL) cholesterol and triglyceride levels, measured by enzymatic colorimetric methods, were included as continuous covariates. Triglyceride levels were logarithmically transformed.

\section{Statistical analysis}

Associations between low back pain and prevalence or risk of diabetes were evaluated by generalized linear modeling for binomial data with a log link, with adjustment for potential confounders. Because of sex differences in 
overall risk and in associations with low back pain ${ }^{23}$ and diabetes ${ }^{24}$ all analyses were carried out separately for women and men. The first analyses included adjustment for age only, and additional adjustment was then introduced for other factors known to influence the risk of both diabetes and low back pain, as BMI, ${ }^{8925}$ physical activity in leisure time ${ }^{10}{ }^{11}$ and smoking. ${ }^{12}{ }^{13}$ In the main analyses, all variables adjusted for were regarded as categorical. Separate tests were performed for interaction between low back pain and each adjustment variable. Because of missing values, somewhat fewer individuals were included in the analyses with complete adjustment. The total number of individuals included in each analysis is shown in the tables.

In particular sensitivity analyses in the cohort study of risk of diabetes, additional adjustment was introduced for duration of education, total cholesterol, HDL cholesterol or triglycerides.

Comorbidity was assessed by including low back pain status at the end of follow-up as a covariate in the analysis of risk of diabetes.

All statistical analyses were carried out using IBM SPSS V.25 (IBM Corp, Armonk, New York, USA).

\section{RESULTS}

\section{Descriptive results}

In the cross-sectional study, a total of 444 women (1.9\%) and 530 men $(2.5 \%)$ reported that they had diabetes (table 1). The percentage of diabetes was only slightly greater among male participants with low back pain than among those without such pain (table 1). The difference was more pronounced among females.

In the cohort study, a total of 586 women $(3.5 \%)$ and 616 men $(4.5 \%)$ reported diabetes at the end of follow-up. This study showed somewhat larger percentages of diabetes at the end of follow-up in the groups with low back pain present than in the groups with pain absent at baseline (table 1). In the cohort study of diabetes risk, the percentages of participants reporting diabetes at the end of follow-up depended markedly on both age and BMI at baseline.

In the cohort study of comorbidity, percentages of diabetes cross-tabulated with low back pain at the end of follow-up among those without either condition at baseline did not show a consistent picture (table 1 ).

\section{Analytic results in the cross-sectional study}

In statistical analyses based on generalized linear models, no association was found between low back pain and prevalence of diabetes in the cross-sectional study (table 2), neither with adjustment for age nor with complete adjustment. In particular, no interaction was observed with linear age $(\mathrm{p}=0.20$ for women and $\mathrm{p}=0.21$ for men $)$ or with sex $(p=0.64)$.

\section{Analytic results in the cohort study}

In the cohort study of women, a statistically significant association was found between low back pain at baseline
Table 1 Number of individuals included in the crosssectional study, the cohort study of diabetes risk and the cohort study of comorbidity

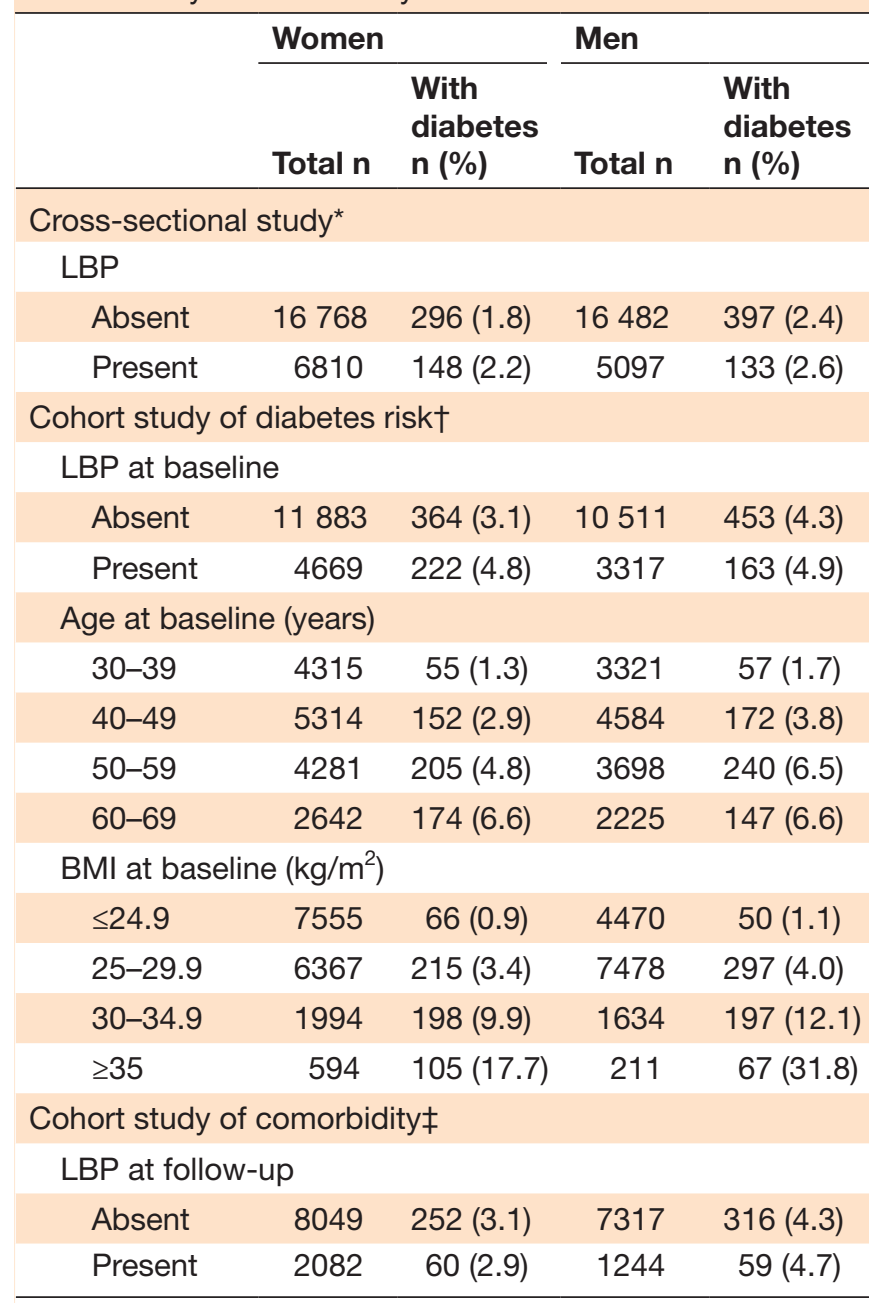

*Includes individuals with information at baseline, with possible diagnosis of diabetes at the same stage.

†Includes individuals without diabetes at baseline, under risk of diabetes at the end of follow-up.

†Includes individuals without diabetes or LBP at baseline, under risk of diabetes and LBP at the end of follow-up.

BMI, body mass index; LBP, low back pain.

and risk of diabetes (table 3 ). After complete adjustment, women with chronic low back pain experienced about $30 \%$ increased risk of diabetes at the end of follow-up. In separate sensitivity analyses excluding all individuals with a diagnosis of diabetes known to have occurred during the first 2 or 4 years of follow-up, slightly stronger relationships were observed (results not shown). No association between low back pain and diabetes was indicated in men (table 3), but the sex difference was not statistically significant $(\mathrm{p}=0.11)$.

Separate adjusted analyses with the original BMI values included as a continuous variable with polynomial effect produced quite similar results to those shown in table 3 . Modeling the age effect by a polynomial also led to almost the same results. Further adjustment for duration of education or serum levels of total cholesterol, HDL 
Table 2 Associations between low back pain and prevalence of diabetes in the cross-sectional study

\begin{tabular}{cll}
\hline & Women & Men \\
\hline Adjustment for age & & \\
\hline PR $(95 \% \mathrm{Cl})$, LBP vs no LBP & $\begin{array}{l}1.12 \\
(0.92 \text { to } 1.36)\end{array}$ & $\begin{array}{l}0.95 \\
(0.78 \text { to } 1.15)\end{array}$ \\
\hline P values & 0.27 & 0.61 \\
\hline Number of individuals included & 23578 & 21579 \\
\hline Complete adjustment* & & \\
\hline PR (95\% Cl), LBP versus no LBP & 1.04 & 0.95 \\
& $(0.84$ to 1.30) & $(0.78$ to 1.17) \\
\hline P values & 0.70 & 0.63 \\
\hline Number of individuals included & 21292 & 20094 \\
\hline
\end{tabular}

${ }^{*}$ Adjustment for age, BMI, physical activity and smoking.

BMI, body mass index; LBP, low back pain; PR, prevalence ratio.

cholesterol or triglycerides did not materially affect risk estimates for baseline low back pain (results not shown).

Considering the risk of diabetes in women, an interaction between age and low back pain at baseline was observed (table 4). The strongest association between low back pain and risk of diabetes was found among women in the lowest age interval 30-39 years. In this group, women with low back pain showed an estimated increase in risk of about $80 \%$. With increasing age, the association in women became weaker, and by the age of 60-69 years, no association remained. No statistically significant interactions were found with other risk factors.

No association between diabetes and chronic low back pain regarded as comorbid conditions at the end of follow-up could be established in either sex (table 5), and no age interaction was found.

Table 3 Associations between baseline low back pain and risk of diabetes at the end of follow-up in the cohort study of individuals without diabetes at baseline

\begin{tabular}{|c|c|c|}
\hline & Women & Men \\
\hline \multicolumn{3}{|l|}{ Adjustment for age } \\
\hline RR (95\% Cl), LBP versus no LBP & $\begin{array}{l}1.40 \\
(1.19 \text { to } 1.64)\end{array}$ & $\begin{array}{l}1.04 \\
\text { (0.87 to } 1.24)\end{array}$ \\
\hline$P$ values & $<0.001$ & 0.68 \\
\hline Number of individuals included & 16552 & 13828 \\
\hline \multicolumn{3}{|l|}{ Adjustment for age and BMI } \\
\hline RR (95\% Cl), LBP versus no LBP & $\begin{array}{l}1.26 \\
(1.07 \text { to } 1.48)\end{array}$ & $\begin{array}{l}1.02 \\
\text { (0.86 to } 1.20)\end{array}$ \\
\hline$P$ values & 0.005 & 0.86 \\
\hline Number of individuals included & 16510 & 13793 \\
\hline \multicolumn{3}{|l|}{ Complete adjustment ${ }^{\star}$} \\
\hline RR $(95 \% \mathrm{Cl})$, LBP versus no LBP & $\begin{array}{l}1.30 \\
(1.09 \text { to } 1.54)\end{array}$ & $\begin{array}{l}1.02 \\
(0.86 \text { to } 1.21)\end{array}$ \\
\hline$P$ values & 0.003 & 0.82 \\
\hline Number of individuals included & 15349 & 13141 \\
\hline
\end{tabular}

*Adjustment for baseline age, BMI, physical activity and smoking.

BMI, body mass index; LBP, low back pain.

\section{DISCUSSION}

In this cohort, an overall relationship was found in women between chronic low back pain at baseline and risk of diabetes after 11 years. The relationship was considerably stronger in women younger than 40 years. In men, no association was observed. No excess comorbidity between diabetes and chronic low back pain was found in the cohort study. The cross-sectional study did not reveal any association.

Our analysis is based on a large population-based data set, with the overwhelming majority of the participants belonging to a homogeneous ethnic group. Less than 3\% of the population had a non-Caucasian background. ${ }^{18}$ The area is representative of Norway, but includes no major cities. The general income is slightly below the average in Norway. ${ }^{18}$ In the period considered here, the health system in Norway was substantially uniform, based on public services. Available information about potential confounders as BMI, physical activity and smoking made it possible to carry out essential adjustments. Former work using data from the HUNT population has shown that BMI is strongly associated with both diabetes ${ }^{26}$ and low back pain. ${ }^{9}$ BMI was categorized into four major groups representing normal weight or underweight, overweight, obesity and severe obesity. This might leave residual confounding by BMI, but separate analyses with $\mathrm{BMI}$ as a continuous variable indicated that this problem was very minor. Unfortunately, relatively large parts of the population did not participate in the surveys.

Taking into account the results of the validity study, ${ }^{19}$ the information supplied by the participants about diabetes most likely reflects nearly the true situation considering the previous diagnoses. It is well known, however, that a substantial proportion of those with diabetes have not received a formal diagnosis, ${ }^{27}$ although this must apply both to participants with and without low back pain. Those suffering from chronic low back pain may still have sought medical attention more frequently than the general population. If this involved drawing blood samples, diabetes may have been detected more easily, generating a false association between low back pain and risk of diabetes. Another possible source of error is reverse causation if undetected diabetes or prediabetes affects the likelihood of experiencing low back pain. Short-term effects of this kind may to some extent be checked by excluding the first part of the follow-up period from the analysis. In this study, exclusion of cases of diabetes reported to occur in the first 2 or 4 years of follow-up did not weaken the association observed among women. The total follow-up period was in any case considerably longer than in comparable studies. ${ }^{416}$

The diagnosis of low back pain was self-reported, but only serious cases lasting for at least 3 months were supposed to be included. Pain intensity was not recorded and pain status in the 11-year period between the HUNT2 and HUNT3 surveys is unknown.

In a Danish study of patients with type 2 diabetes matched against the general population, ${ }^{14}$ the prevalence 
Table 4 Associations between low back pain and risk of diabetes by baseline age, in the cohort study of individuals without diabetes at baseline

\begin{tabular}{|c|c|c|c|c|}
\hline & \multicolumn{2}{|l|}{ Women } & \multicolumn{2}{|l|}{ Men } \\
\hline & No adjustment & Complete adjustment ${ }^{\star}$ & No adjustment & Complete adjustment \\
\hline & $\mathrm{RR}+(95 \% \mathrm{Cl})$ & $\mathrm{RR}+(95 \% \mathrm{Cl})$ & RR† (95\% Cl) & RR† (95\% Cl) \\
\hline \multicolumn{5}{|l|}{ Age (years) } \\
\hline $30-39$ & $2.22(1.30$ to 3.81$)$ & 1.78 (1.03 to 3.07$)$ & $0.78(0.37$ to 1.63$)$ & 0.76 (0.37 to 1.58$)$ \\
\hline $40-49$ & 1.79 (1.30 to 2.47$)$ & 1.58 (1.14 to 2.18$)$ & 1.07 (0.77 to 1.51$)$ & 1.11 (0.80 to 1.54$)$ \\
\hline $50-59$ & 1.39 (1.06 to 1.82$)$ & 1.24 (0.94 to 1.64$)$ & $0.94(0.71$ to 1.24$)$ & $0.87(0.66$ to 1.15$)$ \\
\hline $60-69$ & 0.99 (0.73 to 1.35$)$ & $1.02(0.72$ to 1.44$)$ & $1.25(0.90$ to 1.74$)$ & 1.34 (0.97 to 1.85$)$ \\
\hline $\begin{array}{l}\mathrm{P} \text { values, interaction categorical } \\
\text { age and LBP }\end{array}$ & 0.019 & 0.11 & 0.50 & 0.23 \\
\hline $\begin{array}{l}\mathrm{P} \text { values, interaction linear age } \\
\text { and LBP }\end{array}$ & 0.002 & 0.015 & 0.33 & 0.31 \\
\hline
\end{tabular}

*Adjustment for baseline BMI, physical activity and smoking.

†RR for LBP versus no LBP.

BMI, body mass index; LBP, low back pain.

of low back pain was significantly higher among the patients with diabetes. A cross-sectional study using National Health and Nutrition Examination Survey data from the US adult population found higher prevalence of chronic low back pain among participants with diabetes. ${ }^{15}$ In a study of Spanish twins, ${ }^{4}$ chronic back pain was found to be associated with the prevalence of type 2 diabetes in the cross-sectional analyses, with more consistent associations among women. These results are not in agreement with our cross-sectional results. In the analyses of a 2-4 year follow-up of the Spanish twins, ${ }^{4}$ low back pain was not found to increase the risk of diabetes significantly, but in women the risk estimate was elevated, suggesting a stronger association than in our study. To our knowledge, this is the only other longitudinal study reporting on associations between back pain and diabetes risk.

Studies based on other designs found mixed results regarding a potential association between diabetes and

Table 5 Comorbidity between low back pain and diabetes at follow-up in the cohort study of individuals with neither low back pain nor diabetes at baseline*

\begin{tabular}{|c|c|c|}
\hline & Women & Men \\
\hline \multicolumn{3}{|l|}{ Adjustment for age } \\
\hline $\begin{array}{l}\mathrm{RR}(95 \% \mathrm{Cl}) \text { for diabetes, LBP } \\
\text { versus no LBP }\end{array}$ & $\begin{array}{l}0.90 \\
(0.68 \text { to } 1.19)\end{array}$ & $\begin{array}{l}1.12 \\
(0.86 \text { to } 1.47)\end{array}$ \\
\hline$P$ values & 0.45 & 0.42 \\
\hline Number of individuals included & 10131 & 8561 \\
\hline \multicolumn{3}{|l|}{ Complete adjustment $†$} \\
\hline $\begin{array}{l}\text { RR }(95 \% \text { Cl) for diabetes, LBP } \\
\text { versus no LBP }\end{array}$ & $\begin{array}{l}0.84 \\
(0.63 \text { to } 1.13)\end{array}$ & $\begin{array}{l}0.98 \\
(0.76 \text { to } 1.28)\end{array}$ \\
\hline$P$ values & 0.24 & 0.90 \\
\hline Number of individuals included & 9488 & 8181 \\
\hline
\end{tabular}

*Expressed by relative risk of diabetes comparing individuals with and without LBP at follow-up.

†Adjustment for baseline age, BMI, physical activity and smoking.

BMI, body mass index; LBP, low back pain. back pain. In a Swedish study based on a 4-year follow-up of a large population sample, an increased risk of frequent pain in the back, neck and/or shoulder was observed among men with diabetes without hyperlipidemia, but not among women. ${ }^{16}$ Among orthopedic patients with lumbar spinal stenosis, a higher prevalence of diabetes mellitus was found, compared with patients in the same clinic with a diagnosis of degenerative disc disease or with osteoporotic vertebral fractures. ${ }^{7}$ In a population study of twins in the UK, an association between type 2 diabetes and lumbar intervertebral disc degeneration disappeared after adjustment for BMI. ${ }^{5}$ In a patient material, markers of diabetes progression were associated with the presence of back pain. ${ }^{28}$ A Finnish cross-sectional study showed an association between chronic widespread pain including back pain and both diabetes and prediabetes. ${ }^{29}$

An earlier review of comorbidity between low back pain and other disorders included two cross-sectional studies reporting on diabetes. ${ }^{30}$ In one study, no comorbidity was found after adjustment, and in the other one, a negative association was observed. No comorbidity was found between low back pain and diabetes after adjustment in a German national survey. ${ }^{31}$

In animal models, changes in the vertebral endplates and discs were found in type 2 diabetic rats. ${ }^{32}$ In a mouse model, spinal degenerative changes in the vertebral structure were induced in a prediabetic state. ${ }^{33}$

A positive association between low back pain and risk of diabetes, as found in our study in women, could be ascribed to common underlying risk factors. However, taking into account the adjustment carried out here for BMI, physical activity and smoking, this seems unlikely. Otherwise, it is conceivable that low back pain directly affects factors that are important for later development of diabetes. Thus, low back pain may lead to less physical activity and consequently greater BMI, and in this way also an increased risk of diabetes. It is also possible that occurrence of low back pain is an early indication of 
underlying physiological changes that may subsequently predispose to diabetes.

Inflammation may thus be part of the pathogenesis of both diabetes ${ }^{34}$ and low back pain. ${ }^{35}$ Inflammatory pathways are involved in the pathogenesis of insulin resistance, which is associated with a state of low-grade chronic inflammation in type 2 diabetes. ${ }^{36}$ Inflammatory mediators are also involved in insulin signaling pathways. ${ }^{37}$ Obesity is characterized by a proinflammatory condition with hypertrophied adipose tissue contributing to the level of proinflammatory cytokines. ${ }^{38}$ Pain generated by inflammatory changes mediated by substances released from fat cells may also provide a possible link to increased back pain. Thus, obesity may lead to low back pain through systemic chronic inflammation. ${ }^{9}{ }^{39}$ An inflammatory process has in particular been associated with Modic type 1 vertebral endplate changes seen on MRI in some low back pain patients. ${ }^{40}$

Dyslipidaemia with reduced HDL and elevated triglyceride levels are associated with insulin resistance and type 2 diabetes. ${ }^{41}$ In previous analyses among the HUNT population, the prevalence of low back pain was found to be inversely associated with HDL cholesterol and positively associated with triglycerides, with stronger associations in women than in men. ${ }^{42}{ }^{43}$ This is consistent with the suggestion that low back pain may be related to lumbar artery disease, with atherosclerosis in the feeding arteries producing reduced blood supply and disc degeneration. ${ }^{44}$

Levels of sex hormones may affect the development of diabetes $^{24}$ and thus be responsible for the contrast in associations with low back pain suggested in our study between women and men. Estrogens may have both anti-inflammatory and proinflammatory roles. ${ }^{45}$ Sex differences in diabetes risk have also been linked to differences in body weight, ${ }^{46}$ but this should be less important in our study since we have adjusted for BMI. Psychosocial factors may impact development of diabetes in a sex-specific manner, ${ }^{24}$ and general sex differences in pain perception ${ }^{47}$ may affect the classification of back pain. A difference in risk estimates between women and men was also found in the longitudinal analysis of low back pain as a risk factor for type 2 diabetes in the Spanish twin study. ${ }^{4}$

In this study, the association between low back pain and diabetes was stronger in younger women. For type 2 diabetes, the disease onset and progression may be different in young people. ${ }^{48}$ In the cross-sectional HUNT2 study, type 1 diabetes (including latent autoimmune diabetes in adults) must be represented in all age groups, although most of the cases are likely of type 2 diabetes. ${ }^{49}$ In contrast, our cohort study only comprises cases of diabetes diagnosed after the age of 30 years, and the vast majority will be cases of type 2 diabetes. Even in the youngest group of participants in our study, the majority of cases likely have type 2 diabetes, and type differences according to age can hardly explain the age differences in risk estimates found by us.
Although a positive association was found among women in our cohort study, no such association could be demonstrated in the cross-sectional data. Cross-sectional results do not take into account temporal relationships and may to a larger extent reflect a combination of different disease categories and underlying effects. This may also explain the heterogeneity in results considering other cross-sectional studies. It is more surprising in our study that no comorbidity was observed considering information on diabetes and low back pain collected at the same time at the end of follow-up in the cohort data. The contrast with the positive association seen among women in the standard analysis of risk may be related to the difference in time lag. The dependence of the association in women on age at baseline may also be important, with reports of back pain in the comorbidity study being made about 11 years after those considered in the standard analyses.

\section{CONCLUSION}

Women without diabetes who suffer from chronic low back pain, have an increased risk of experiencing diabetes 11 years later. The association is most pronounced among women younger than 40 years and diminishes with increasing age. In men, no association can be established. Among participants who do not suffer from diabetes or chronic low back pain, no comorbidity can be demonstrated over an 11-year interval. These results should be confirmed in cohort studies in populations elsewhere.

\section{Author affiliations}

${ }^{1}$ Department of Research, Innovation and Education, Division of Clinical Neuroscience, Oslo University Hospital, Oslo, Norway

${ }^{2}$ Department of Mathematics, University of Bergen, Bergen, Norway

${ }^{3}$ Department of Neuromedicine and Movement Science, NTNU, Norwegian University of Science and Technology, Trondheim, Norway

${ }^{4}$ Norwegian Advisory Unit on Headaches, St. Olavs University Hospital, Trondheim, Norway

${ }^{5}$ Department of Public Health and Nursing, Faculty of Medicine and Health Sciences, HUNT Research Centre, NTNU, Norwegian University of Science and Technology, Levanger, Norway

${ }^{6}$ Department of Public Health and Nursing, Faculty of Medicine and Health Sciences, K.G. Jebsen Center for Genetic Epidemiology, NTNU, Norwegian University of Science and Technology, Trondheim, Norway

${ }^{7}$ Department of Endocrinology, St. Olavs Hospital, Trondheim University Hospital, Trondheim, Norway

${ }^{8}$ Faculty of Medicine, University of Oslo, Oslo, Norway

Acknowledgements The Nord-Trøndelag Health Study (The HUNT Study) is a collaboration between HUNT Research Centre (Faculty of Medicine and Health Sciences, Norwegian University of Science and Technology (NTNU)), NordTrøndelag County Council, Central Norway Regional Health Authority, and the Norwegian Institute of Public Health.

Contributors $\mathrm{InH}$ and $\mathrm{IH}$ contributed to analysis and interpretation of data. InH wrote the paper. IH, KH, EPS, BOÅ and JAZ revised the manuscript. All the authors contributed to the study design and have read and approved the paper.

Funding The authors have not declared a specific grant for this research from any funding agency in the public, commercial or not-for-profit sectors.

Competing interests None declared.

Patient consent Not required. 
Ethics approval The work was approved by the Regional Committee for Medical and Health Research Ethics in Central Norway, and HUNT was also approved by the Norwegian Data Inspectorate.

\section{Provenance and peer review Not commissioned; externally peer reviewed.}

Data sharing statement The data set analysed belongs to a third party, the HUNT study (the Nord-Trøndelag Health Study). The authors of the current manuscript are not affiliated with the project as such but have been given permission to analyse the data after obtaining the necessary Norwegian permits. Because of the confidentiality requirements according to Norwegian law, a data set of this kind with information from a complete county at the individual level cannot be made public. However, research groups wishing to analyse data from the HUNT study may apply to the HUNT organization (http://www.ntnu.edu/hunt) to get access to the data, after having obtained the permits needed according to Norwegian law.

Open access This is an open access article distributed in accordance with the Creative Commons Attribution Non Commercial (CC BY-NC 4.0) license, which permits others to distribute, remix, adapt, build upon this work non-commercially, and license their derivative works on different terms, provided the original work is properly cited, appropriate credit is given, any changes made indicated, and the use is non-commercial. See: http://creativecommons.org/licenses/by-nc/4.0/

\section{REFERENCES}

1. Guariguata L, Whiting DR, Hambleton I, et al. Global estimates of diabetes prevalence for 2013 and projections for 2035. Diabetes Res Clin Pract 2014;103:137-49.

2. Buchbinder R, Blyth FM, March LM, et al. Placing the global burden of low back pain in context. Best Pract Res Clin Rheumatol 2013;27:575-89.

3. Eivazi M, Abadi L. Low back pain in diabetes mellitus and importance of preventive approach. Health Promot Perspect 2012;2:80-8.

4. Dario A, Ferreira M, Refshauge K, et al. Mapping the association between back pain and type 2 diabetes: a cross-sectional and longitudinal study of adult Spanish twins. PLoS One 2017;12:e0174757.

5. Fabiane SM, Ward KJ, latridis JC, et al. Does type 2 diabetes mellitus promote intervertebral disc degeneration? Eur Spine $J$ 2016;25:2716-20.

6. Liu X, Pan F, Ba Z, et al. The potential effect of type 2 diabetes mellitus on lumbar disc degeneration: a retrospective single-center study. J Orthop Surg Res 2018;13:52.

7. Anekstein $Y$, Smorgick $Y$, Lotan R, et al. Diabetes mellitus as a risk factor for the development of lumbar spinal stenosis. Isr Med Assoc J 2010;12:16-20.

8. Abdullah A, Peeters A, de Courten M, et al. The magnitude of association between overweight and obesity and the risk of diabetes: a meta-analysis of prospective cohort studies. Diabetes Res Clin Pract 2010;89:309-19.

9. Heuch I, Heuch I, Hagen K, et al. Body mass index as a risk factor for developing chronic low back pain: a follow-up in the NordTrøndelag Health Study. Spine 2013;38:133-9.

10. Smith AD, Crippa A, Woodcock J, et al. Physical activity and incident type 2 diabetes mellitus: a systematic review and doseresponse meta-analysis of prospective cohort studies. Diabetologia 2016;59:2527-45.

11. Heuch I, Heuch I, Hagen K, et al. Is there a U-shaped relationship between physical activity in leisure time and risk of chronic low back pain? A follow-up in the HUNT Study. BMC Public Health 2016;16:306.

12. Willi $\mathrm{C}$, Bodenmann $\mathrm{P}$, Ghali WA, et al. Active smoking and the risk of type 2 diabetes: a systematic review and meta-analysis. JAMA 2007;298:2654-64.

13. Leboeuf-Yde C. Smoking and low back pain. A systematic literature review of 41 journal articles reporting 47 epidemiologic studies. Spine 1999;24:1463-70.

14. Molsted S, Tribler J, Snorgaard O. Musculoskeletal pain in patients with type 2 diabetes. Diabetes Res Clin Pract 2012;96:135-40.

15. Hassoon A, Bydon M, Kerezoudis $P$, et al. Chronic low-back pain in adult with diabetes: NHANES 2009-2010. J Diabetes Complications 2017;31:38-42.

16. Pico-Espinosa OJ, Skillgate E, Tettamanti G, et al. Diabetes mellitus and hyperlipidaemia as risk factors for frequent pain in the back, neck and/or shoulders/arms among adults in Stockholm 2006 to 2010 - Results from the Stockholm Public Health Cohort. Scand J Pain 2017;15:1-7.

17. Krokstad S, Langhammer A, Hveem K, et al. Cohort Profile: the HUNT Study, Norway. Int J Epidemiol 2013;42:968-77.
18. Holmen J, Midthjell K, Krüger $\varnothing$. The Nord-Trøndelag Health Study 1995-97 (HUNT 2): objectives, contents, methods and participation. Norw J Epidemiol 2003;13:19-32.

19. Midthjell K, Holmen J, Bjørndal A, et al. Is questionnaire information valid in the study of a chronic disease such as diabetes? The Nord-Trøndelag diabetes study. J Epidemiol Community Health 1992;46:537-42.

20. Bogduk N. Management of chronic low back pain. Med J Aust 2004;180:79-83.

21. Langhammer A, Krokstad S, Romundstad P, et al. The HUNT study: participation is associated with survival and depends on socioeconomic status, diseases and symptoms. BMC Med Res Methodol 2012;12:143.

22. Kurtze N, Rangul V, Hustvedt BE, et al. Reliability and validity of selfreported physical activity in the Nord-Trøndelag Health Study (HUNT 2). Eur J Epidemiol 2007;22:379-87.

23. Hartvigsen J, Hancock MJ, Kongsted A, et al. What low back pain is and why we need to pay attention. Lancet 2018;391:2356-67.

24. Kautzky-Willer A, Harreiter J, Pacini G. Sex and gender differences in risk, pathophysiology and complications of type 2 diabetes mellitus. Endocr Rev 2016;37:278-316.

25. Shiri R, Karppinen J, Leino-Arjas $P$, et al. The association between obesity and low back pain: a meta-analysis. Am J Epidemiol 2010;171:135-54.

26. Carlsson S, Midthjell K, Tesfamarian MY, et al. Age, overweight and physical inactivity increase the risk of latent autoimmune diabetes in adults: results from the Nord-Trøndelag health study. Diabetologia 2007;50:55-8.

27. Khunti K, Mani H, Achana F, et al. Systematic review and metaanalysis of response rates and diagnostic yield of screening for type 2 diabetes and those at high risk of diabetes. PLoS One 2015;10:e0135702

28. Rinaldo L, McCutcheon BA, Gilder H, et al. Diabetes and back pain: markers of diabetes disease progression are associated with chronic back pain. Clin Diabetes 2017;35:126-31.

29. Mäntyselkä P, Miettola J, Niskanen L, et al. Persistent pain at multiple sites-connection to glucose derangement. Diabetes Res Clin Pract 2009;84:e30-e32

30. Hestbaek L, Leboeuf-Yde C, Manniche C. Is low back pain part of a general health pattern or is it a separate and distinctive entity? A critical literature review of comorbidity with low back pain. $J$ Manipulative Physiol Ther 2003;26:243-52.

31. Schneider S, Mohnen SM, Schiltenwolf M, et al. Comorbidity of low back pain: representative outcomes of a national health study in the Federal Republic of Germany. Eur J Pain 2007;11:387-97.

32. Fields AJ, Berg-Johansen B, Metz LN, et al. Alterations in intervertebral disc composition, matrix homeostasis and biomechanical behavior in the UCD-T2DM rat model of type 2 diabetes. J Orthop Res 2015:33:738-46.

33. Illien-Jünger S, Lu Y, Qureshi SA, et al. Chronic ingestion of advanced glycation end products induces degenerative spinal changes and hypertrophy in aging pre-diabetic mice. PLoS One 2015;10:e0116625.

34. Donath MY. Multiple benefits of targeting inflammation in the treatment of type 2 diabetes. Diabetologia 2016;59:679-82.

35. Hashem LE, Roffey DM, Alfasi AM, et al. Exploration of the interrelationships between obesity, physical inactivity, inflammation, and low back pain. Spine 2018;43:1218-24.

36. Wieser V, Moschen AR, Tilg H. Inflammation, cytokines and insulin resistance: a clinical perspective. Arch Immunol Ther Exp 2013:61:119-25.

37. Zand H, Morshedzadeh N, Naghashian F. Signaling pathways linking inflammation to insulin resistance. Diabetes Metab Syndr 2017;11(Suppl 1):S307-S309.

38. Asghar A, Sheikh N. Role of immune cells in obesity induced low grade inflammation and insulin resistance. Cell Immunol 2017;315:18-26.

39. Tilg H, Moschen AR. Adipocytokines: mediators linking adipose tissue, inflammation and immunity. Nat Rev Immunol 2006;6:772-83.

40. Fayad F, Lefevre-Colau MM, Rannou F, et al. Relation of inflammatory modic changes to intradiscal steroid injection outcome in chronic low back pain. Eur Spine J 2007;16:925-31.

41. Krauss RM. Lipids and lipoproteins in patients with type 2 diabetes. Diabetes Care 2004;27:1496-504.

42. Heuch I, Heuch I, Hagen K, et al. Associations between serum lipid levels and chronic low back pain. Epidemiology 2010;21:837-41.

43. Heuch I, Heuch I, Hagen K, et al. Do abnormal serum lipid levels increase the risk of chronic low back pain? The Nord-Trøndelag Health Study. PLoS One 2014;9:e108227.

44. Kauppila LI. Can low-back pain be due to lumbar-artery disease? Lancet 1995;346:888-9.

45. Straub $\mathrm{RH}$. The complex role of estrogens in inflammation. Endocr Rev 2007;28:521-74. 
46. Midthjell K, Krüger O, Holmen J, et al. Rapid changes in the prevalence of obesity and known diabetes in an adult Norwegian population. The Nord-Trøndelag Health Surveys: 1984-1986 and 1995-1997. Diabetes Care 1999;22:1813-20.

47. Keogh E. Sex and gender differences in pain: a selective review of biological and psychosocial factors. J Men's Health Gender 2006;3:236-43.
48. Lascar N, Brown J, Pattison H, et al. Type 2 diabetes in adolescents and young adults. Lancet Diabetes Endocrinol 2018;6:69-80.

49. Hagen K, Åsvold BO, Midthjell K, et al. Inverse relationship between type 1 diabetes mellitus and migraine. Data from the NordTrøndelag Health Surveys 1995-1997 and 2006-2008. Cephalalgia 2018;38:417-26. 